\title{
Performance Evaluation of an Organic Rankine Cycle Fed by Waste Heat Recovered from $\mathrm{CO}_{2}$ Capture Section
}

\author{
V.Tola ${ }^{1 *}$, M.Finkenrath ${ }^{2}$ \\ ${ }^{1}$ University of Cagliari, DIMCM, Cagliari, Sardinia, Italy \\ ${ }^{2}$ Kempten University of Applied Sciences, Kempten, Germany \\ E-mail: ${ }^{1}$ vittorio.tola@dimcm.unica.it
}

Received 16 March 2015, Revised 27 October 2015, Accepted 09 November 2015

\begin{abstract}
Natural gas-fueled combined cycle (NGCC) allows to reach the best performance among power plants fed by fossil fuels, but causes considerable $\mathrm{CO}_{2}$ emissions. With the aim of reducing greenhouse gases impact, NGCC could be integrated with post-combustion $\mathrm{CO}_{2}$ removal systems, typically based on chemical solvents like amines, that cause very large net efficiency penalties (about 9-12 percentage points at $90 \%$ overall $\mathrm{CO}_{2}$ capture). To reduce these high capture penalties, exhaust gas recirculation (EGR) has been studied. To further enhance the overall plant efficiency, the recovery of available low temperature heat from the solvent-based $\mathrm{CO}_{2}$ removal systems could be also performed. Low temperature heat is available in flue gas coolers $\left(80-100^{\circ} \mathrm{C}\right)$, in the amine reboiler water cooling $\left(130-140^{\circ} \mathrm{C}\right)$ and in the splitter condenser $\left(100-130^{\circ} \mathrm{C}\right)$. This waste thermal energy could be recovered by means of an Organic Rankine Cycle (ORC) that is able to convert heat into electricity efficiently even at comparably low temperatures. N-Butane was found to be as the most promising organic working fluid for the cycle operating temperatures and pressures. ORC produces additional electrical power improving the global performance of the power plant, for example, up to 1-1.5 percentage points in efficiency.
\end{abstract}

Keywords: $\mathrm{ORC} ; \mathrm{CO}_{2}$ capture; low temperature heat recovery; $\mathrm{NGCC}$.

\section{Introduction}

Greenhouse gases emissions are largely increasing in the last decades leading to a carbon dioxide $\left(\mathrm{CO}_{2}\right)$ concentration in the atmosphere over $400 \mathrm{ppm}$. Reductions in $\mathrm{CO}_{2}$ emissions from power plants fed by fossil fuels are expected to significantly contribute to the fulfillment of national and international greenhouse gas regulations, such as the Kyoto protocol and the European Union Emission Trading Scheme. In this framework Carbon Capture and Storage (CCS) is crucial to reduce $\mathrm{CO}_{2}$ emissions. In the IEA scenario for limiting the rise in global temperatures to $2-2.4{ }^{\circ} \mathrm{C}$, CCS alone accounts for $19 \%$ of the total $\mathrm{CO}_{2}$ emissions reduction by 2050 [1]. Remaining $81 \%$ are due to energy system efficiency increase (38\%), fuel switching $(20 \%)$, renewable $(17 \%)$ and nuclear $(6 \%)$. Furthermore, natural gas-fired power plants are expected to contribute to about $30 \%$ of the total installed power generation capacity equipped with CCS [1].

Many studies, however, have shown that $\mathrm{CO}_{2}$ capture from power plants is both very capital- and energyintensive [2-5]. For an example, integration of a postcombustion $\mathrm{CO}_{2}$ removal system with a natural gas-fueled combined cycle (NGCC) reduces the net plant efficiency of 8-11 percentage points (at $90 \%$ overall $\mathrm{CO}_{2}$ capture) [6-7]. In post-combustion capture, $\mathrm{CO}_{2}$ is absorbed from the stack gases using chemical solvents, typically a mixture of water and monoethanolamine (MEA). MEA is largely used, despite its high energy requirements in comparison to other amines, since it is one of the most proven and widespread technologies [8-12], although in a medium-term perspective better options should become available. In a chemical absorption process, $\mathrm{CO}_{2}$ removal takes place in an absorber column, where $\mathrm{CO}_{2}$ reacts with the lean solvent to form a $\mathrm{CO}_{2}$-rich solvent. The process for $\mathrm{CO}_{2}$ removal requires a large amount of thermal energy, at about $140^{\circ} \mathrm{C}$, to desorb the $\mathrm{CO}_{2}$ from the rich-solvent. This thermal energy is obtained condensing steam extracted from the combined cycle. Steam extraction leads to a substantial power reduction in the steam cycle. Other sources of power reduction are the exhaust gas fans, solvent circulation pumps, and $\mathrm{CO} 2$ compression up to a pressure suitable for transport and storage, $\mathrm{CO}_{2}$ removal and pumping [4,13-14]. Significant R\&D projects are dedicated to both the research of less expensive solvents as well as the development of more efficient capture and compression processes [15-16].

A first step that has been proposed for NGCC in order to reduce the high exhaust volumes and to increase the low $\mathrm{CO}_{2}$ concentration in the flue gas is the exhaust gas recirculation (EGR). EGR leads to a reduction of both specific energy demand of the separation process and costs associated with the capture unit [17-19]. Studies show that a percentage of exhaust gas recycled back to the GT ranging between 30 and $50 \%$ cause a small impact on the gas turbine turbomachinery components [20]. Efficiency losses are reduced by approximately 1\% [21-23] and capital expenditure for the capture unit is reduced by $20-30 \%$ [24]. Combustion with the EGR environment has been shown to be feasible in existing dry low $\mathrm{NO}_{\mathrm{x}}$ burners [25].

Despite the low attention that recovery of available low temperature waste heat from capture plants and related process equipment has gained in the past, this approach can allow one to further increase the overall plant efficiency. At 
first, low temperature heat is available in flue gas coolers, upstream of the $\mathrm{CO}_{2}$ capture unit, typically at a temperature in the range of $80-100^{\circ} \mathrm{C}$. Further low-grade heat sources are located in the desorption column. The amine reboiler water cooling that could reach temperatures of up to 130 $140^{\circ} \mathrm{C}$ and the stripper condenser, which operates at around $100-130{ }^{\circ} \mathrm{C}$. Thermal energy of these various sources could be utilized in a system that is able to convert heat into electricity efficiently even at comparably low temperatures. This paper evaluates the performance impact of recovering low temperature heat with an Organic Rankine Cycle (ORC). By producing additional electrical power in the heat recovery system, the global performance of the power plant can be improved. This study indicates a theoretical entitlement of up to additional 1-1.5 percentage points in efficiency that could be gained by integrating ORC technology with a post-combustion capture system for natural gas combined cycles.

In this paper different ORC configurations have been considered for thermal energy recovery at various temperature levels from the above-mentioned sources. The study focuses on simultaneous low-grade heat recovery in a single ORC loop. Heat recovery options that are discussed include series, parallel or cascaded arrangements of heat exchangers. Different organic operating fluids, including carbon dioxide, R245fa, and N-butane were considered for the analysis. The ORC performance was evaluated for nbutane found as the most promising organic working fluid by a parametric study. Optimum cycle operating temperatures and pressures were identified to evaluate the most efficient approach for low temperature heat recovery.

\section{Natural Gas Combined Cycle with $\mathrm{CO}_{2}$ Capture \\ 2.1 Plant Configuration and Performance}

The plant considered in this study is a medium-size (about $400 \mathrm{MW}_{\mathrm{e}}$ ) natural gas fired combined cycle plant based on a gas turbine integrated with a heat recovery steam generator (HRSG) and a triple pressure steam cycle. Figure 1 shows a simplified scheme of the NGCC plant.

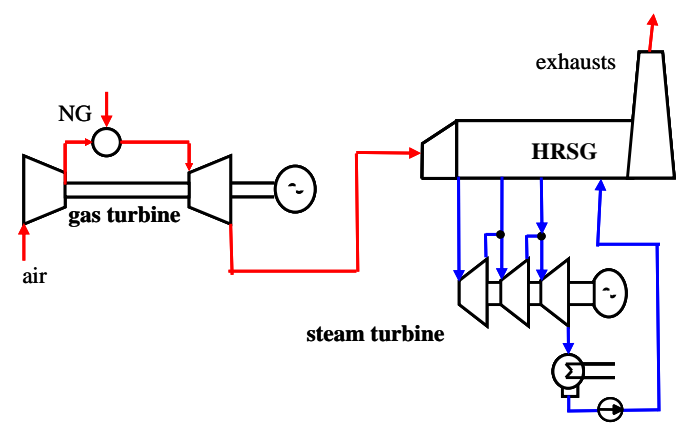

Figure 1. Simplified scheme of the NGCC plant.

The NGCC was also studied in the more complex configuration considering a $\mathrm{CO}_{2}$ capture and compression system in the so-called NGCC-CCS plant. As mentioned, chemical absorption with amine-based solvents is currently considered the most suitable option for $\mathrm{CO}_{2}$ removal from flue gases. In the present study, despite its high energy requirement for the regeneration process, the $\mathrm{CO}_{2}$ removal system was based on a simple typical post-combustion capture system based on a $30 \mathrm{wt}-\%$ mixture of MEA and water. Figure 2 shows a simplified scheme of the $\mathrm{CO}_{2}$ capture section.

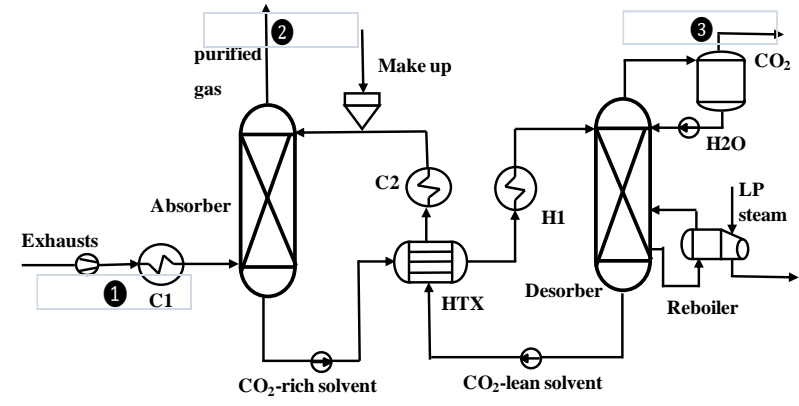

Figure 2. Simplified scheme of the $\mathrm{CO}_{2}$ capture section.

Exhaust gas is cooled to $30-50{ }^{\circ} \mathrm{C}(\mathrm{C} 1)$ and enters into the absorption column (Absorber), where the $\mathrm{CO}_{2}$ is absorbed by the aqueous MEA solution flowing counter flow. The $\mathrm{CO}_{2}$-free gas (purified gas) is discharged from the top of the absorber and sent to the stack, while the $\mathrm{CO}_{2}$ rich solvent is withdrawn from the bottom and sent to the regeneration column, the so-called stripper (Desorber). The higher stripper temperature (about $100^{\circ} \mathrm{C}$ ) is obtained by cooling the $\mathrm{CO}_{2}$-lean solvent (HTX) and through a heat exchanger (H1). Inside the stripper a $\mathrm{CO}_{2}$-water vapor mixture is released from the $\mathrm{CO}_{2}$-rich solvent through the reboiler heat. In the upper section of the regeneration column a large fraction of steam condensates, whereas the $\mathrm{CO}_{2}$-rich flow is sent to the compression section. The $\mathrm{CO}_{2}-$ lean solvent extracted from the bottom is cooled (HTX and C2) and recirculated back to the absorption column.

Downstream the $\mathrm{CO}_{2}$ removal section requirements for $\mathrm{CO}_{2}$ transport and storage are matched by means of a conditioning and compression section. In particular a pressure of $11 \mathrm{MPa}$ and $\mathrm{CO}_{2}$ purity above $99.5 \%$ are requested. $\mathrm{CO}_{2}$ is compressed up to $8 \mathrm{MPa}$ in gaseous phase through a three-stage intercooled compressor and then in liquid phase through a pump.

The power section performance and $\mathrm{CO}_{2}$ removal performance were evaluated through simulation models based on the commercial software packages GateCycle ${ }^{\mathrm{TM}}$ and HYSYS $^{\mathrm{TM}}$, respectively. The analysis is based on fundamental thermodynamic analyses in order to evaluate the general entitlement of heat recovery options based on ORC technology. It is important to note that it does not include a detailed site-specific capture plant analysis, or an engineering- or component-level design and feasibility analysis. These would be required next steps prior to an implementation of the suggested heat recovery options.

Table 1 shows main operating parameters of the NGCC.

Table 1. Main Operating Parameters of the NGCC Power Plant.

\begin{tabular}{ll}
\hline Gas turbine & \\
\hline Ambient temperature ${ }^{\circ} \mathrm{C}$ & 15 \\
Compressor ratio & 18.0 \\
Exhaust mass flow kg/s & 659 \\
Exhaust temperature ${ }^{\circ} \mathrm{C}$ & 642 \\
\hline Steam cycle & \\
\hline HP steam temperature ${ }^{\circ} \mathrm{C}$ & 565 \\
HP steam pressure bar & 162.6 \\
IP steam temperature ${ }^{\circ} \mathrm{C}$ & 565 \\
IP steam pressure bar & 24.2 \\
LP steam temperature ${ }^{\circ} \mathrm{C}$ & 311 \\
LP steam pressure bar & 4.5 \\
Condenser pressure $\mathrm{kPa}$ & 3.5 \\
Cooling water temperature ${ }^{\circ} \mathrm{C}$ & 17 \\
Cooling water temperature rise ${ }^{\circ} \mathrm{C}$ & 6.7 \\
Temperature difference in the condenser ${ }^{\circ} \mathrm{C}$ & 3 \\
\hline
\end{tabular}


Assuming a fuel chemical power input of 751.0 MW (corresponding to $15.01 \mathrm{~kg} / \mathrm{s}$ of natural gas), the NGCC shows a net efficiency of $59.2 \%$ (LHV) and a plant net power of $444.6 \mathrm{MW}$. The $\mathrm{CO}_{2}$ emitted by the plant is equal to $336 \mathrm{~g} / \mathrm{kWh}$.

Lower performance is expected for the NGCC-CCS power plant. Main operating parameters of the $\mathrm{CO}_{2}$ removal section are given in Table 2.

Table 2. Main Operating Parameters of the $\mathrm{CO}_{2}$ Removal Section.

\begin{tabular}{lc}
\hline Absorber temperature ${ }^{\circ} \mathrm{C}$ & 45 \\
MEA mass fraction & 0.30 \\
Reboiler specific thermal energy $\mathrm{MJ} / \mathrm{kg}_{\mathrm{CO} 2}$ & 4.58 \\
\hline
\end{tabular}

Figure 3 shows both plant net power and plant net efficiency of the NGCC-CCS as a function of $\mathrm{CO}_{2}$ removal rate. Different carbon dioxide removal efficiencies, in the range 0.7-0.9, were considered in this study. In fact, although $90 \%$ is the most common $\mathrm{CO}_{2}$ removal target, lower severe targets (down to 70\%) were also considered to evaluate influence of $\mathrm{CO}_{2}$ removal efficiency on the overall performance since the reboiler heat requirement strongly depends on $\mathrm{CO}_{2}$ removal rate.

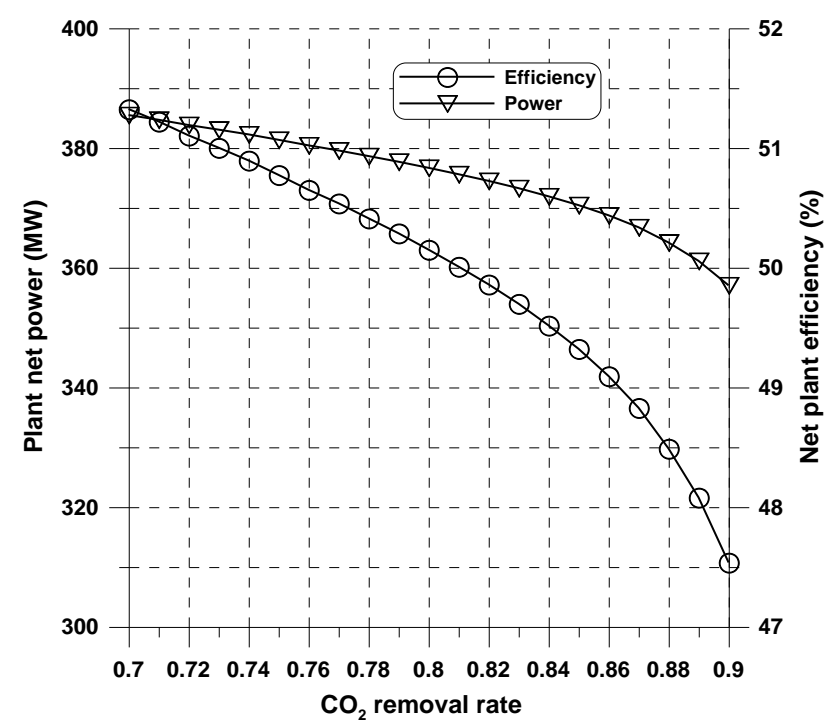

Figure 3. NGCC-CCS Net Power and Net Efficiency as a Function of $\mathrm{CO}_{2}$ Removal Rate.

As expected Figure 3 shows that the introduction of the $\mathrm{CO}_{2}$ removal system remarkably reduces plant performance. Plant net power decreases to $385.5 \mathrm{MW}$ assuming a $\mathrm{CO}_{2}$ removal of $70 \%$, whereas it drops down to $357.0 \mathrm{MW}$ for a $\mathrm{CO}_{2}$ removal of $90 \%$. Consequently, net plant efficiency is reduced to $51.3 \%$ at $70 \%$ of $\mathrm{CO}_{2}$ removal and $47.5 \%$ at $90 \% \mathrm{CO} 2$ removal. Globally the power reduction generated by the $\mathrm{CO}_{2}$ removal process is equal to $19.7 \%: 15.2 \%$ is due to the amine heat requirement, $2.4 \%$ to the $\mathrm{CO}_{2}$ compression train and $1.7 \%$ to the capture system electrical consumption.

Figure 4 shows the amount of $\mathrm{CO}_{2}$ captured and emitted, electrical power and specific thermal energy required by the $\mathrm{CO}_{2}$ removal section, as a function of $\mathrm{CO}_{2}$ removal rate.

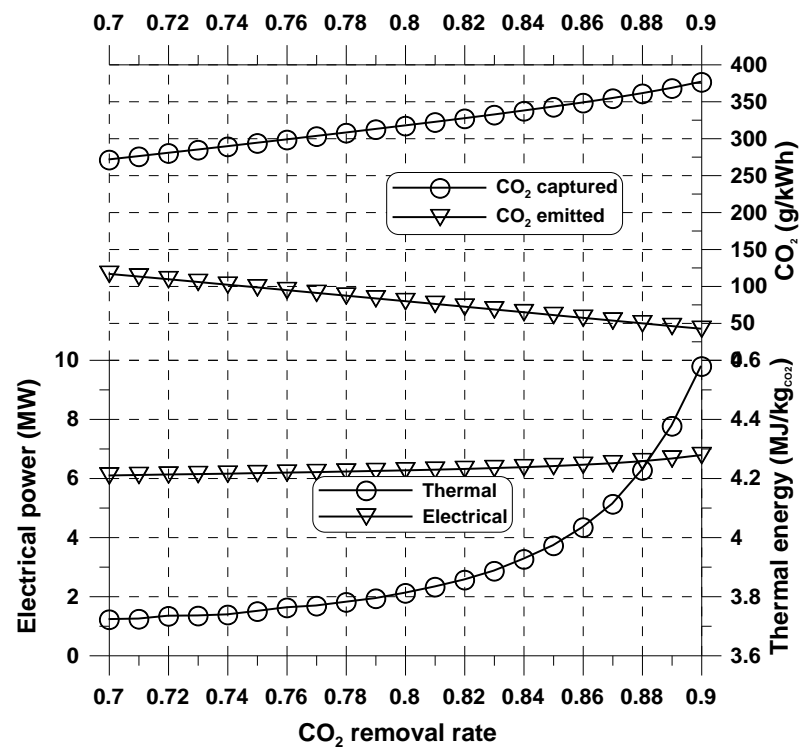

Figure 4. $\mathrm{CO}_{2}$ captured and emitted, electrical power requirements and specific thermal energy of the $\mathrm{CO}_{2}$ removal section as a function of $\mathrm{CO}_{2}$ removal rate.

Obviously, the amounts of $\mathrm{CO}_{2}$ captured and emitted are increased and decreased respectively, increasing the $\mathrm{CO}_{2}$ removal rate. At a $\mathrm{CO}_{2}$ removal rate of 0.90 , the amount of $\mathrm{CO}_{2}$ captured is equal to $376.3 \mathrm{~g} / \mathrm{kWh}$, whereas the $\mathrm{CO}_{2}$ emitted is reduced to $41.8 \mathrm{~g} / \mathrm{kWh}$.

Electrical power requirements range between 6 and 7 MW, slightly increasing with $\mathrm{CO}_{2}$ removal rate, due to the larger power required by the solvent pump. Specific thermal energy required by the reboiler is about $3.75 \mathrm{MJ} / \mathrm{kg}$ assuming a $\mathrm{CO}_{2}$ removal rate equal to 0.7 and increases up to $4.6 \mathrm{MJ} / \mathrm{kg}$ for a $\mathrm{CO}_{2}$ removal rate equal to 0.9 .

Table 3 reports mass flow, temperature, pressure and gas composition of exhaust gas entering (1) and exiting (2) the absorber and of the $\mathrm{CO}_{2}$-rich flow (3) leaving the removal section.

Table 3. Gas Characteristics in the $\mathrm{CO}_{2}$ Removal Section.

\begin{tabular}{lcccc}
\hline & & $\mathbf{1}$ & $\mathbf{2}$ & $\mathbf{3}$ \\
\hline Mass flow & $\mathrm{kg} / \mathrm{s}$ & 659.0 & 621.2 & 37.7 \\
Temperature & ${ }^{\circ} \mathrm{C}$ & 81.0 & 44.4 & 38.4 \\
Pressure & $\mathrm{bar}$ & 1.07 & 1.01 & 3.0 \\
$\mathrm{CO}_{2}$ mass flow & $\mathrm{kg} / \mathrm{s}$ & 41.46 & 4.14 & 37.32 \\
\hline Gas composition & & & & \\
\hline $\mathrm{N}_{2}$ & $\%$ & 74.19 & 77.07 & 0.04 \\
$\mathrm{O}_{2}$ & $\%$ & 11.86 & 12.31 & trace \\
$\mathrm{CO}_{2}$ & $\%$ & 4.05 & 0.42 & 97.43 \\
$\mathrm{Ar}$ & $\%$ & 0.88 & 0.92 & trace \\
$\mathrm{H}_{2} \mathrm{O}$ & $\%$ & 9.01 & 9.27 & 2.53 \\
\hline
\end{tabular}

\subsection{Exhaust Gas Recirculation}

Exhaust gas recirculation (EGR) has been developed mainly for oxy-fuel plants fed by coal, where exhaust gas is partially recycled back to the boiler in order to control flame temperature. EGR could be also applied to gas turbines and NGCC. In this option, exhaust gas is partially extracted at the exit of the HRSG, cooled down to nearambient temperature and sent back to the compressor of the gas turbine, where it is mixed with fresh ambient air [26]. Differently by oxy-coal plants, EGR penalizes combined cycle performance, in particular compressor performance. With respect to compressing ambient air, a higher 
temperature of the air-flue gas mixture entering the compressor and a higher heat capacity of the recirculated gas, which is more humid, are obtained [27]. On the contrary, in an NGCC with $\mathrm{CO}_{2}$ post-combustion capture, EGR has been proposed earlier in order to improve the capture efficiency and substantially reduce capture equipment costs $[22,27]$. In fact EGR leads to a higher $\mathrm{CO}_{2}$ concentration in the flue gas and a reduced size of the $\mathrm{CO}_{2}$ capture unit. However, a greater $\mathrm{CO}_{2}$ partial pressure in the exhaust gas due to EGR reduces the energy requirements for the amine system, and enhances the performance of the power plant system. While a detailed evaluation of EGR from gas-fired power generation was beyond the scope of this paper, this general effect is illustrated in Figure 5 that shows both the net power plant and net plant efficiency as a function of the EGR ratio. EGR ratio is defined as the ratio between the exhaust gas recirculated back to the compressor and the total exhaust gas mass flow. Reducing cooling temperature enhances compressor performance; for this reason NGCC-CCS performance is calculated for two different exhaust gas cooling temperatures, $45^{\circ} \mathrm{C}$ and $30^{\circ} \mathrm{C}$, which has been considered to be a practical lower limit for EGR cooling for economic considerations.

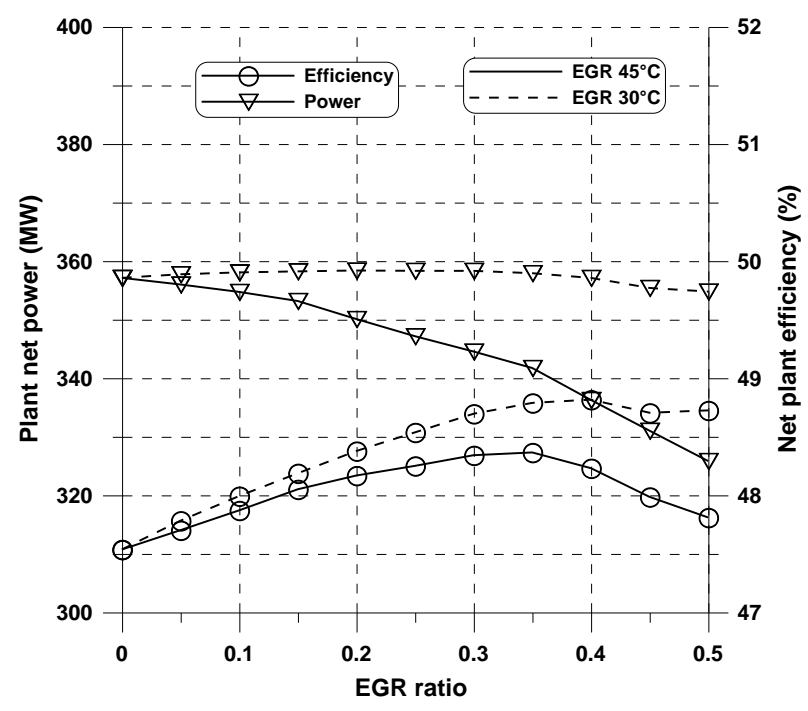

Figure 5. NGCC-CCS net power and net efficiency as a function of EGR ratio and temperature.

Figure 5 shows that in both conditions the EGR enhances plant net efficiency. In particular an overall optimum in terms of net plant efficiency could be expected at EGR ratios between 0.3 and 0.4 for both gas cooling temperatures. Net efficiency increases up to $50.3 \%$ with gas cooling down to $30{ }^{\circ} \mathrm{C}$. On the contrary, NGCC-CCS net power is just barely affected by EGR ratio in case of cooling temperature of $30^{\circ} \mathrm{C}$, whereas EGR notably reduces plant net power assuming a cooling temperature of $45^{\circ} \mathrm{C}$.

\section{Organic Rankine Cycle}

\subsection{Low Temperature Heat Sources}

As mentioned before, low temperature heat rejected from power plants could be a potential energy source for enhancing plant performance. Differently from coal-fired plants, in combined cycles the use of recovered heat in condensate and/or feed water preheating to avoid extraction flows from the steam turbine is not a feasible option. Starting from this consideration the recovery of available low temperature heat from the solvent-based $\mathrm{CO}_{2}$ removal system has been considered for a further increase of the overall NGCC-CCS performance. In particular this paper examines the opportunity for recovering this low temperature heat by a bottoming Organic Rankine Cycle (ORC) [28-29].

Different sources of available low temperature heat from solvent-based $\mathrm{CO}_{2}$ removal systems can be theoretically used for heat recovery in an ORC. In general the following major low-grade heat sources can be identified: exhaust gas cooler, amine reboiler condensate cooling, stripper condenser, $\mathrm{CO}_{2}$ compressor intercoolers and lean solvent coolers.

Cooling down exhaust gas from a NGCC (for EGR and/or $\mathrm{CO}_{2}$ capture) leads to a discharge of a large amount of low temperature $\left(80-100{ }^{\circ} \mathrm{C}\right)$ thermal energy. Besides a large amount of heat is also available from the amine-based post-combustion $\mathrm{CO}_{2}$ capture system. In particular potential heat sources are the stripper condenser (at $100-120^{\circ} \mathrm{C}$ ) and the amine reboiler condensate cooling (at about 130-140 ${ }^{\circ} \mathrm{C}$ ). In the stripper condenser a mixture of $\mathrm{CO}_{2}$ and water vapor condensates making available for heat recovery at a variable temperature both sensible and latent heat. In a NGCC plant the saturated hot water (in the order of 4 bar and at up to $140{ }^{\circ} \mathrm{C}$ ) exiting the reboiler unit is often reinjected to the main steam cycle. However extracting heat from the hot condensate for feeding the Organic Rankine Cycle (ORC) affects the steam cycle performance only in the case of condensate cooling temperature lower than $50^{\circ} \mathrm{C}$.

Additional sensible heat could be recovered from $\mathrm{CO}_{2}$ compressor intercoolers, however the temperature of this available waste heat depends on the actual $\mathrm{CO}_{2}$ compressor chain configuration. As previously mentioned, the $\mathrm{CO}_{2}$ must be pressurized to at least 110 bar for transport and storage. At first, the $\mathrm{CO}_{2}$ compression process is carried out above the critical pressure (about 74 bar) in gaseous phase through a three-stage intercooled compressor and then in liquid phase through a pump. $\mathrm{CO}_{2}$ compressors are generally characterized by low pressure ratios in order to reduce $\mathrm{CO}_{2}$ compression work, although this does require a larger number of compression stages. Low compression ratios however are less suitable for heat recovery in an ORC, since the temperature level of waste heat from compressor intercoolers would be insufficient. Therefore heat recovery from the compressor intercoolers is not analyzed in this study. Furthermore, low temperature heat could be provided from cooling the lean $\mathrm{CO}_{2}$ solvent. Since generally this thermal energy is almost fully used to preheat the rich solvent coming from the absorption column, this potential heat source is also not included in this study.

\subsection{ORC Configurations and Fluids}

In this paper different ORC configurations have been studied to perform a simultaneous heat recovery from sources at different temperature. Studied configurations include in series, in parallel or cascaded layouts. In series or cascaded layouts are potentially simpler in design, but their application typically requires a notable temperature difference between the waste heat sources. In comparison, a parallel heat recovery layout comes with operational challenges related to controlling different and potentially fluctuating mass flow through each heat exchanger. Nonetheless, a parallel heat recovery layout allows for simultaneous heat recovery from different waste heat 
sources at similar temperature levels. Since waste heat sources at similar temperature are available in a postcombustion capture section from a NGCC, in this paper a parallel configuration of heat recovery has been chosen

Depending on the temperature of the waste heat source, different suitable organic working fluids can be selected. For this specific application, three fluids were analyzed as potential ORC working fluids taking the operating conditions into account: carbon dioxide $\left(\mathrm{CO}_{2}\right)$, N-Butane and penta-fluoro-propane (R245fa). Each fluid shows different properties and that could be matched with the available waste heat temperature levels by adjusting the cycle operating pressures. Table 4 shows the saturation pressure of carbon dioxide, N-Butane and R245fa as a function of temperature [30].

Table 4. Saturation $\mathrm{T}$ and $\mathrm{P}$ for $\mathrm{CO}_{2}, \mathrm{~N}$-Butane and R245fa

\begin{tabular}{|c|c|c|c|}
\hline $\begin{array}{c}\text { Temperature } \\
\left({ }^{\circ} \mathrm{C}\right)\end{array}$ & $\begin{array}{l}\text { Pressure } \\
\text { (bar) }\end{array}$ & $\begin{array}{l}\text { Pressure } \\
\text { (bar) }\end{array}$ & $\begin{array}{l}\text { Pressure } \\
\text { (bar) }\end{array}$ \\
\hline & $\mathrm{CO}_{2}$ & n-Butane & R245fa \\
\hline 10 & 44.9 & 1.5 & 0.8 \\
\hline 20 & 57.3 & 2.1 & 1.2 \\
\hline 30 & 72.1 & 2.8 & 1.8 \\
\hline 40 & - * & 3.8 & 2.5 \\
\hline 50 & - & 4.9 & 3.4 \\
\hline 60 & - & 6.4 & 4.6 \\
\hline 70 & - & 8.1 & 6.0 \\
\hline 80 & - & 10.1 & 7.8 \\
\hline 90 & - & 12.5 & 10.0 \\
\hline 100 & - & 15.3 & 12.6 \\
\hline \multicolumn{4}{|c|}{${ }^{*} \mathrm{CO}_{2}$ critical point at 73.8 bar and $31^{\circ} \mathrm{C}$} \\
\hline
\end{tabular}

$\mathrm{CO}_{2}$ could be an interesting choice as organic working fluid, due to synergies in the fluid handling or safety infrastructure with the $\mathrm{CO}_{2}$ capture system, lower costs as organic fluid and a better match with the exhaust gas cooling curve, due to the lack of vaporization in the operating range under consideration. However, $\mathrm{CO}_{2}$ shows some disadvantages, in particular a higher pump work, which leads to a low plant performance, due to the supercritical conditions, and in general potentially higher equipment costs due to the very high operating pressure required. In fact $\mathrm{CO}_{2}$ condensation at $20^{\circ} \mathrm{C}$ takes place at 57 bar, whereas, at this temperature n-butane and R245fa both condensates at significantly lower pressures of 2.1 bar and 1.2 bar, respectively. For this reason in this study $\mathrm{CO}_{2}$ was not pursued as a working fluid. R245fa has similar characteristics as n-butane, but it performs slightly worse than n-butane. For this reason n-butane was selected as organic fluid for more detailed analysis in this paper [31].

\subsection{Results}

As previously mentioned, in this study the ORC recovers waste heat simultaneously at slightly different temperature by using parallel waste heat exchanger arrangements. Due to the parallel flow configuration all heat exchangers operate at the same selected upper operating pressure of n-butane. In addition heat exchangers do not include superheating section, therefore N-Butane exits the evaporator at saturation conditions, with the highest operating temperature. As a consequence, the maximum pressure in the cycle is specified by saturation properties of n-butane. Table 5 lists the main characteristics of the Organic Rankine Cycle studied in this paper.
Table 5. Organic Rankine Cycle Parameter Range.

\begin{tabular}{lr}
\hline Parameter & Range \\
\hline Vapor fraction at the turbine inlet & 1 \\
Pressure at the turbine entry bar & $6-15$ \\
Temperature at the turbine entry ${ }^{\circ} \mathrm{C}$ & $58-99$ \\
Pressure at the condenser bar & 2.5 \\
Temperature at the condenser ${ }^{\circ} \mathrm{C}$ & 25 \\
Minimum $\Delta T$ at the heat exchanger ${ }^{\circ} \mathrm{C}$ & 5 \\
\hline
\end{tabular}

A condenser pressure equal to 2.5 bar has been fixed for N-Butane, corresponding to a condensation temperature of $25{ }^{\circ} \mathrm{C}$. Since waste heat sources are available at different temperatures, a sensitivity analysis has been carried out as a function of the maximum pressure of N-Butane in the ORC. A maximum ORC pressure ranging between 6 and 15 bar has been considered, that corresponds to a saturation temperature between 58 and $99{ }^{\circ} \mathrm{C}$. A minimum temperature difference of $5^{\circ} \mathrm{C}$ has been assumed in the heat exchangers between the heat source and the organic working fluid.

A higher pressure of organic fluid leads to a higher evaporation temperature, reducing the amount of heat that can be recovered. On the other hand a higher pressure of organic fluid in the evaporator maximizes the turbine work, while additional required pump work to achieve the high pressure is comparably low. For these reasons the heat recovery can be optimized through a trade-off between key operating parameters.

Figure 6 shows the waste heat recovered as a function of the ORC maximum pressure for a scenario with $30 \%$ EGR. The figure reports the total heat recovered and the heat recovered from each of the three different heat sources (exhaust gas, amine reboiler condensate cooling and stripper condenser)

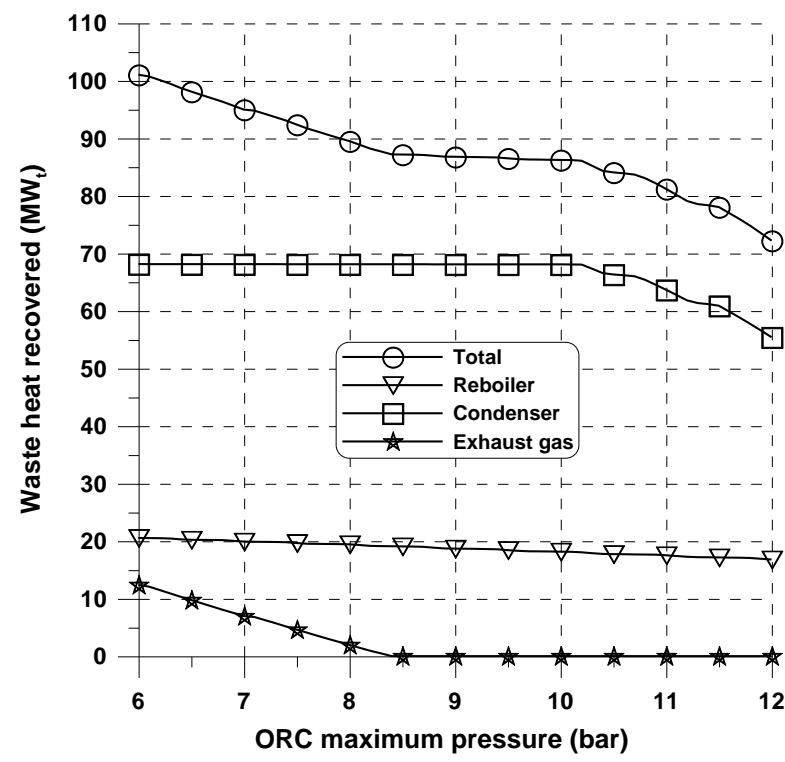

Figure 6. Waste heat recovered as a function of ORC operating pressure.

As mentioned above, an increase in the ORC maximum operating pressure reduces the overall waste heat recovery, and the single heat recovered, although not all the sources are impacted by a similar intensity. The amount of waste heat recovered from amine reboiler condensate cooling slightly decreases from 20.5 to $16.8 \mathrm{MW}$, increasing the maximum operating pressure from 6 bar to 12 bar. The 
waste heat recovered is not affected significantly by the maximum cycle pressure, due to the comparably high temperature (up to $140{ }^{\circ} \mathrm{C}$ ) of the saturated water that exits the amine reboiler. Furthermore, an increase in the operating pressure results in a constant waste heat recovery from the stripper condenser (about $68 \mathrm{MW}$ ) until a maximum pressure of about 10.5 bar is reached. A higher pressure reduces the possible waste heat recovery from the condenser, which is assumed to have a water exit temperature slightly higher than $100{ }^{\circ} \mathrm{C}$, since the pinch point minimum temperature difference is reached. A minimum amount of waste heat equal to $55.4 \mathrm{MW}$ is recovered for an operating pressure of 12 bar. In contrast, waste heat recovery from exhaust gas cooling is possible only at very low evaporation pressures of n-butane. In particular the heat recovery would be $12.4 \mathrm{MW}$ at 6 bar, while no waste heat recovery from exhaust gas cooling would be possible at maximum evaporation pressure higher than 8.3 bar. Figure 6 shows also the total amount of waste heat that potentially could be recovered by an Organic Rankine Cycle based on n-butane as a working fluid. This is about $101.1 \mathrm{MW}$ at 6 bar operating pressure. A relatively moderate reduction in heat recovery takes place by increasing operating pressures up to 10.5 bar (84.1 MW), while at higher pressures a notable reduction of recovered heat can be noticed, mainly due to reductions in heat recovery from the stripper condenser. A minimum of 72.2 MW of waste heat is recovered at an operating pressure of 12 bar.

For the two main waste heat sources available (stripper condenser and amine reboiler condensate cooling) the $Q-T$ diagrams are shown in Figures $7 \mathrm{a}$ and $7 \mathrm{~b}$ and Figures $8 \mathrm{a}$ and $8 \mathrm{~b}$, respectively. The $Q-T$ diagrams show N-Butane preheating and vaporizing processes as a function of waste heat recovered. In particular, Figures $7 \mathrm{a}$ and $8 \mathrm{a}$ show $Q-T$ diagrams for an operating pressures of n-butane equal to 6 and 8 bar, whereas Figures $8 \mathrm{a}$ and $8 \mathrm{~b}$ show $Q-T$ diagrams for a pressure of 10 and 12 bar.

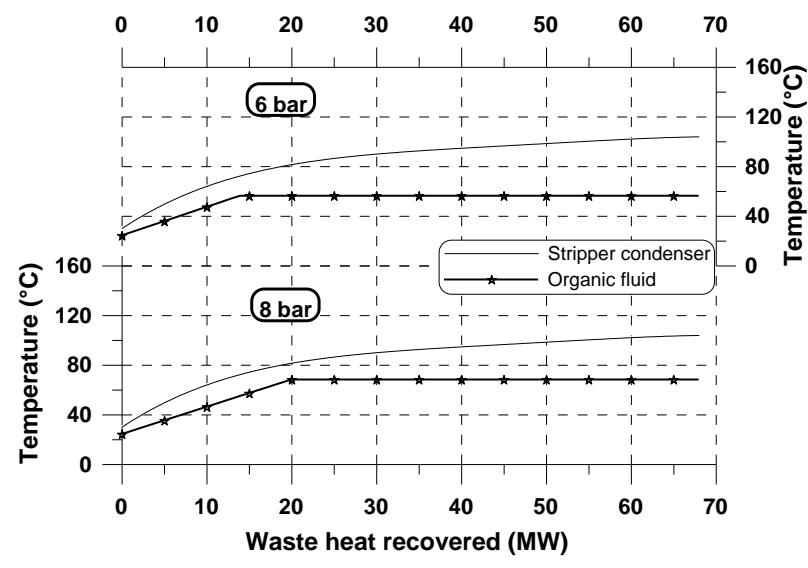

Figure 7a. Q-T diagram for stripper condenser.

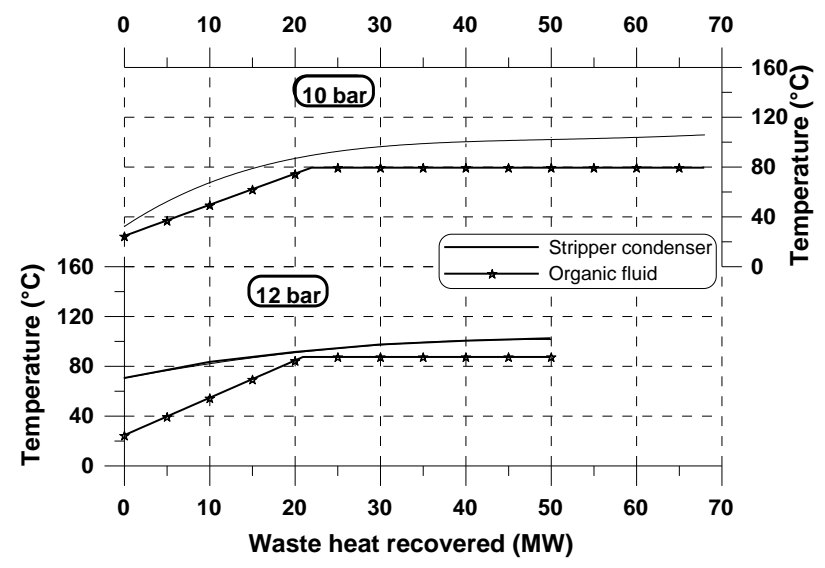

Figure 7 b. Q-T diagram for stripper condenser.

Figure 7 shows that waste heat recovered is not influenced by an organic fluid operating pressure lower than 10 bar.

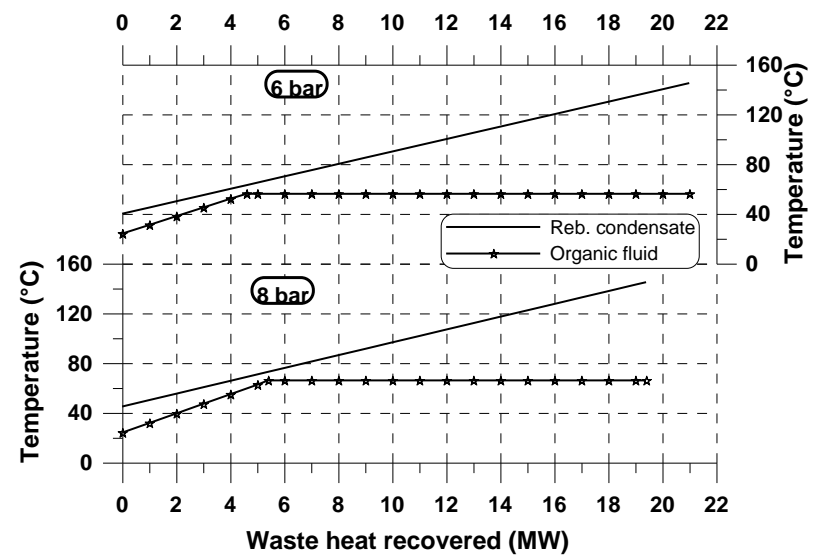

Figure 8a. Q-T diagram for amine reboiler.

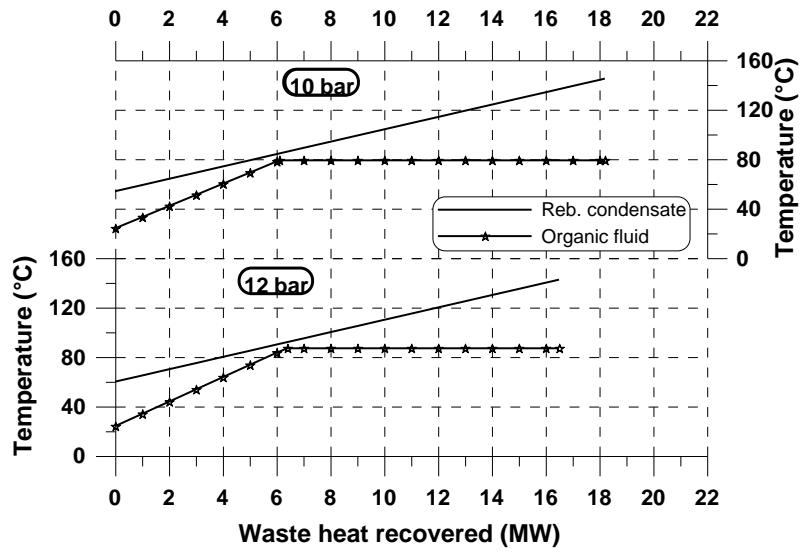

Figure 8b. Q-T diagram for amine reboiler.

Figure 9 shows the ORC net efficiency and the ORC net power as a function of ORC maximum pressure. In particular, Figure 9 shows the total ORC net power and the corresponding net power produced by ORC from each of the three different heat sources considered. 


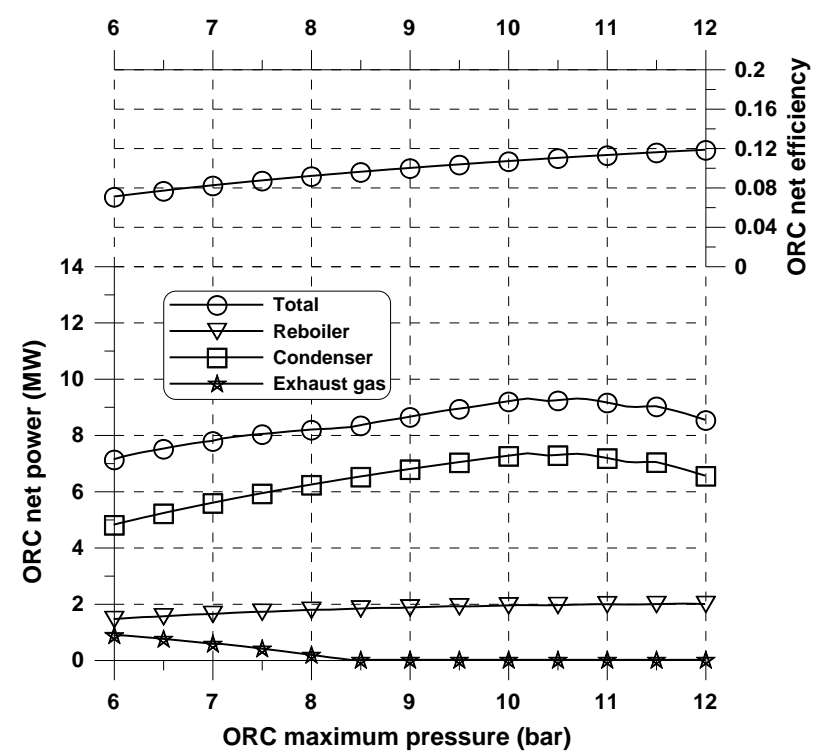

Figure 9. ORC net power and efficiency as a function of ORC operating pressure.

Unlike waste heat recovery, ORC net efficiency increases with ORC maximum pressure. In particular, for a reference scenario based on $30 \%$ EGR fraction and a condenser pressure equal to 2.5 bar, cycle net efficiency increases from $7.1 \%$ (6 bar) to $11.8 \%$ (12 bar). As a consequence of this opposite trend, the net power generated by the ORC system is maximum at about 10.5 bar maximum operating pressure. The maximum net power that can be generated is slightly higher than 9.3 MW (about $2.6 \%$ of the reference NGCC-CCS power) at a total lowtemperature heat input of about $84 \mathrm{MW}$. Since the largest amount of waste heat is recovered from the stripper condenser, the main contribution to the net Organic Rankine Cycle power stems from this heat source. Also the maximum power generated by waste heat from stripper condenser is at about 10.5 bar.

The ORC performance has also been calculated as a function of EGR ratio. This analysis has been carried out having fixed the n-butane maximum pressure to 10.5 bar (corresponding to an evaporation temperature equal to 82 ${ }^{\circ} \mathrm{C}$ ), in order to guarantee a maximized Organic Rankine Cycle net power output. As a consequence of this choice, only two waste heat sources have been taken into account: the amine reboiler condensate cooling and the stripper condenser. An increase of EGR ratio impacts negatively the Organic Rankine Cycle power. In fact an increasing EGR ratio reduces the exhaust gas mass flow entering the $\mathrm{CO}_{2}$ removal system and increases the $\mathrm{CO}_{2}$ concentration in the exhaust gas, and hence it reduces the capture energy penalties and consequently the waste heat available. Figure 10 shows both the ORC efficiency and power as a function of the EGR ratio. $\begin{array}{lllllllllll}0 & 0.05 & 0.1 & 0.15 & 0.2 & 0.25 & 0.3 & 0.35 & 0.4 & 0.45 & 0.5\end{array}$

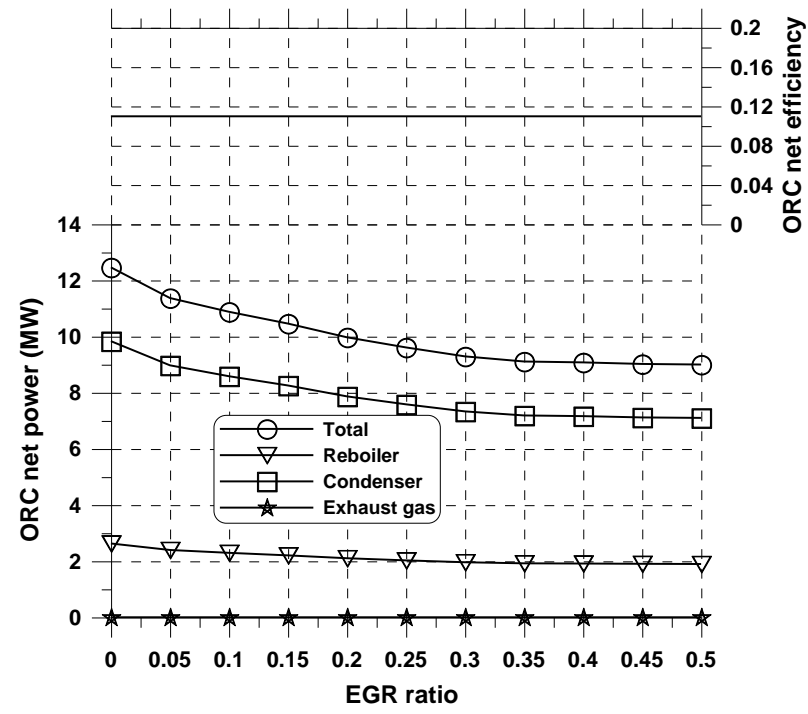

Figure 10. ORC net power as a function of EGR ratio.

As expected, ORC net efficiency is not influenced by the EGR ratio, depending only on the cycle operating parameters. On the contrary, the ORC power reduces with increasing the EGR ratio. Without any exhaust gas recirculation the ORC could provide an extra power of 12.5 MW. Due to the lower waste heat recovery the ORC extra power is reduced increasing EGR, reaching 9.0 MW at an EGR fraction of 0.5 .

Finally the potential impact of EGR and ORC on the total plant performance of the NGCC with post-combustion capture has been obtained. Figure 11 shows the net power and net efficiency of NGCC-CCS plant (with or without Organic Rankine Cycle integration) as a function of the EGR ratio. Differently from baseline plant results shown in Figures 3-5, an absorber column temperature of $30^{\circ} \mathrm{C}$ has been considered in the $\mathrm{CO}_{2}$ removal section in order to match temperature of exhaust gas recirculated. In this way, better plant performance is obtained.

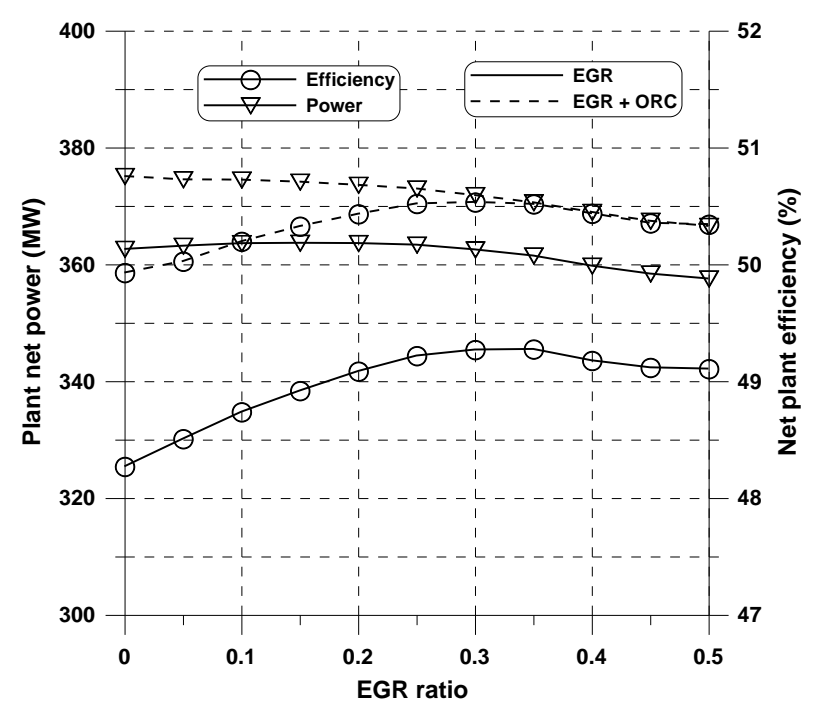

Figure 11. Net plant power and efficiency with and without ORC as a function of EGR ratio. 
As reported on Figure 5, an increase in the exhaust gas recirculation slightly influences the NGCC-CCS net power. In fact, power is maximum at EGR ratio equal to 0.15 , but NGCC-CCS net power is about $360 \mathrm{MW}$ with an EGR ratio ranging between 0 and 0.5 . NGCC-CCS net efficiency is more influenced by EGR ratio, varying between 48.2 and $49.3 \%$ for the same EGR ratio range. Figure 11 shows also the effect of integrating the Organic Rankine Cycle with the NGCC-CCS power plant in terms of net power and net efficiency. The integration of an Organic Rankine Cycle with the $\mathrm{CO}_{2}$ capture systems of an NGCC-CCS would allow to increase the plant net power of about 9-12 MW, depending on EGR ratio. The overall plant efficiency could be increased up to $1-1.5 \%$, depending on EGR ratio. The maximum net efficiency of the NGCC-CCS under investigation thereby rises to $50.5 \%$ (LHV), for an EGR ratio equal to 0.3 , with an equivalent $8.7 \%$ of efficiency penalty compared to the $\mathrm{NGCC}$ without $\mathrm{CO}_{2}$ removal.

\section{Conclusions}

This paper analyses the recovery of low-grade heat from $\mathrm{CO}_{2}$-capture processes for natural gas combined cycles by using Organic Rankine Cycle (ORC) technology. Potential waste-heat sources are identified and most appropriate ORC system layouts are discussed. Under the assumption that $\mathrm{N}$ Butane is identified as the more suitable ORC working fluid, and low-grade heat sources are utilized in parallel in a single ORC loop, the net power generated by the ORC system is maximum at about 10.5 bar maximum operating pressure. The maximum net power generated by the ORC system under investigation is slightly higher than $2.5 \%$ of reference NGCC-CCS power, with a ORC efficiency equal to $11.0 \%$. Globally an overall power plant net efficiency improvement of more than one percentage point is estimated introducing an ORC. An additional increase of $1 \%$ in the efficiency can be gained introducing Exhaust Gas Recirculation (EGR). As a consequence the maximum net efficiency of the reference NGCC-CCS could thereby rise to $50.5 \%$ (LHV), for an EGR ratio equal to 0.3, with an equivalent 8.7 percentage points of efficiency penalty compared to the $\mathrm{NGCC}$ without $\mathrm{CO}_{2}$ removal.

$\begin{array}{ll}\text { Nomenclature } & \\ p & \text { Pressure } \\ T & \text { Temperature } \\ \eta & \text { Efficiency } \\ \text { Acronyms } & \\ C C S & \text { Carbon Capture and Storage } \\ E G R & \text { Exhaust Gas Recirculation } \\ H R S G & \text { Heat Recovery Steam Generator } \\ L H V & \text { Lower Heating Value } \\ M E A & \text { MonoEthanolAmine } \\ N G C C & \text { Natural Gas Combined Cycle } \\ O R C & \text { Organic Rankine Cycle } \\ W H R & \text { Waster Heat Recovery }\end{array}$

\section{References}

[1] IEA Energy Technology Perspectives 2010. Available: http://www.iea.org (Accessed February 23, 2015)

[2] S. E. Rubin, Chen C., Rao A. B., "Cost and performance of fossil fuel power plants with $\mathrm{CO}_{2}$ capture and storage”, Energy Policy, 35, 4444-4454, 2007.
[3] J. Davison, "Performance and costs of power plants with capture and storage of $\mathrm{CO}_{2}$ ", Energy, 32, 7 11631176, 2007.

[4] V. Tola, A. Pettinau, "Power generation plants with carbon capture and storage: A techno-economic comparison between coal combustion and gasification technologies", Applied Energy, 113, 1461-1474, 2014.

[5] N. Smith, G. Miller, I. Aandi, R. Gadsden, J. Davison, "Performance and costs of $\mathrm{CO}_{2}$ capture at gas fired power plants", Energy Procedia, 37, 2443-2452, 2013.

[6] C. Biliyok, H. Yeung, "Evaluation of natural gas combined cycle power plant for post-combustion $\mathrm{CO}_{2}$ capture integration", Int. J. Greenhouse Gas Control, 19, 396-405, 2013.

[7] P. L. Mores, E. Godoy, S. F. Mussati, N. J. Scenna, "A NGCC power plant with a $\mathrm{CO}_{2}$ post-combustion capture option. Optimal economics for different generation/capture goals", Chem. Eng. Res. Des., 92, 1329-1354, 2013.

[8] A. L. Kohl, R. B. Nielsen, Gas Purification $5^{\text {th }}$ Ed. Houston, Texas: Gulf publishing Company, 1997.

[9] F. H. Geuzebroek, L. H. J. Schneiders, G. J. C. Kraaijveld, P. H. M. Feron, "Exergy analysis of alkanolamine-based $\mathrm{CO} 2$ removal unit with Aspen Plus", Energy, 29, 1241-1248, 2004.

[10] C. Alie, L. Backham, E. Croiset, P. L. Douglas, "Simulation of $\mathrm{CO}_{2}$ capture using MEA scrubbing: a flowsheet decomposition method", Energy Convers. Management, 46, 475-487, 2005.

[11] M. R. M. Abu-Zahra, L. H. J. Schneiders, J. P. M. Niederer, P. H. M. Feron, G. F. Versteeg, " $\mathrm{CO}_{2}$ capture from power plants. Part I. A parametric study of the technical performance based on monoethanolamine", Int. J. Greenhouse Gas Control, I, 135-142, 2007.

[12] M. R. M. Abu-Zahra, J. P. M. Niederer, P. H. M. Feron, G. F. Versteeg, " $\mathrm{CO}_{2}$ capture from power plants. Part II. A parametric study of the economical performance based on monoethanolamine", Int. J. Greenhouse Gas Control, I, 135-142, 2007.

[13] G. Cau, V. Tola, P. Deiana, "Comparative performance assessment of USC and IGCC power plants integrated with $\mathrm{CO}_{2}$ capture systems", Fuel, 116, 820-833, 2014.

[14] P.A.M. Ystad, O. Bolland, M. Hillestad, "NGCC and hard-coal power plant with $\mathrm{CO}_{2}$ capture based on absorption”, Energy Procedia, 27, 33-44, 2012.

[15] S. Rubin, H. Mantripragada, A. Marks, P. Versteeg, J. Kitchin, "The outlook for improved carbon capture technology". Progress Energy Combustion Sci., 38, 630-671, 2012.

[16] K. Kadono, A. Suzuki, M. Iijima, T. Ohishi, H. Tanaka, T. Hirata, M. Kondo, "New Energy Efficient Processes and Newly Developed Absorbents for Flue Gas $\mathrm{CO}_{2}$ Capture", Energy Procedia, 37, 1785-1792.

[17] M. Finkenrath, T. P. Ursin., S. Hoffmann, M. Bartlett, A. Evulet, M. J. Bowman, A. Lynghjem, J. Jakobsen, "Performance and cost analysis of novel gas turbine cycle with $\mathrm{CO}_{2}$ capture", in ASME 2007: Proceedings of the ASME Turbo Expo, Montreal, Canada, Paper GT 2007-27764. 
[18] K. Jordal, P.A.M. Ystad, R. Anantharaman, A. Chikukwa, O. Bolland, "Design-point and part-load considerations for natural gas combined cycle plants with post combustion capture", Int. J. Greenhouse Gas Control, 11, 271-282, 2012.

[19] H. Li, M. Ditaranto, D. Berstad, "Technologies for increasing $\mathrm{CO}_{2}$ concentration in exhaust gas from natural gas-fired power production with postcombustion, amine-based $\mathrm{CO}_{2}$ capture”, Energy, 36, 1124-1133, 2011.

[20] N. Sipocz, A. Tobiesen, M. Assadi, "Integrated modeling and simulation of a $400 \mathrm{MW}$ NGCC power plant with $\mathrm{CO}_{2}$ capture", Energy Procedia, 4, 19411948, 2011.

[21] Z. Amrollahi, I. S. Ertesvåg, O. Bolland, “Optimized process configurations of post-combustion $\mathrm{CO}_{2}$ capture for natural-gas-fired power plant - Exergy analysis", Int. J. Greenhouse Gas Control, 5, 13931405, 2011.

[22] H. Li, G. Haugen, M. Ditaranto, D. Berstad, K. Jordal, "Impacts of exhaust gas recirculation (EGR) on the natural gas combined cycle integrated with chemical absorption $\mathrm{CO}_{2}$ capture technology", Energy Procedia, 4, 1411-1418, 2011.

[23] N. Sipocz, A. Tobiesen, "Natural gas combined cycle power plants with $\mathrm{CO} 2$ capture - opportunities to reduce cost", Int. J. Greenhouse Gas Control, 7, 98$106,2012$.

[24] P. E. Røkke, "Environmental use of natural gas in a gas turbine" Doctoral dissertation, Norwegian University of Science and Technology, Trondheim, 2006.
[25] A. T. Evulet, A. M. El Kady, A. R. Brand, D. Chinn, "On the performance nd Operability of GE's Dry Low $\mathrm{NO}_{\mathrm{x}}$ Combustor utilizing Exhaust Gas Recirculation for Post Combustion Carbon Capture", Energy Procedia, 1, 3809-3816, 2009.

[26] P. E. Røkke, J. E. Hustad, "Exhaust Gas Recirculation in Gas Turbines for Reduction of $\mathrm{CO}_{2}$ Emissions; Combustion Testing with Focus on Stability and Emissions", Int. J. Thermodynamics, 8, 167-173, 2005.

[27] C. Botero, M. Finkenrath, M. Bartlett, R. Chu, G. Choi, D. Chinn, "Redesign, Optimization, and Economic Evaluation of a Natural Gas Combined Cycle with the Best Integrated Technology $\mathrm{CO}_{2}$ Capture", Energy Procedia, 1, 3835-3842, 2009.

[28] S. Karellas, A. Schuster, "Supercritical Fluid Parameters in Organic Rankine Cycle Applications", Int. J. Thermodynamics, 11, 101-108, 2008.

[29] A. Lazzaretto, G. Manente, "A New Criterion to Optimize ORC Design Performance using Efficiency Correlations for Axial and Radial Turbines", Int. J. Thermodynamics, 17, 173-181, 2014.

[30] NIST Chemistry WebBook [Online]. Available: http://webbook.nist.gov/chemistry/ (Accessed March 4, 2015).

[31] G. Ast, H. Kopecek, J. Gomez, P. Huck, T. Frey, B. Wilmsen, F. Gruber, "Experimental investigation of an organic Rankine cycle prototype plant being developed to boost the electric output of gas engine power stations" ICEF2009: Proceedings of the ASME Internal Combustion Engine Division Fall Technical Conference, Charleston, SC, Paper 14064.2009. 